\title{
https://doi.org/10.46813/2021-136-067 \\ ACCELERATING OF THE ELECTRONS OF ELECTRON BUNCHES IN A WAVEGUIDE LOADED DIELECTRIC STRUCTURE
}

\author{
A.F. Linnik, I.N. Onishchenko, O.L. Omelayenko, V.I. Pristupa, G.V. Sotnikov, V.S. Us \\ National Science Center "Kharkov Institute of Physics and Technology”, Kharkiv, Ukraine \\ E-mail: aflinnik@kipt.kharkov.ua
}

\begin{abstract}
The paper presents some results of experimental studies of the excitation of wake fields and the acceleration of electrons in waveguide-dielectric structures (DS) upon injection of a sequence of electron bunches into them. Experiments have shown an increase in the amplitude of the wake wave and the acceleration of a small fraction of electrons when the wavelength of the excited field is equal to the doubled bunch length. A simple physical model of the observed phenomenon is given. Also, the paper proposes a method for accelerating a part of each electron bunch in the steady-state mode of the resonator dielectric structure. Some of the electrons are "cut out" by the collimator and enter the accelerating phase of the previously excited wake wave. The wave is displaced due to the difference in the distances traveled by the wave and the accelerated part of the electrons.
\end{abstract}

PACS: 41.75.Lx; 52.40.Mj

\section{INTRODUCTION}

A new method of accelerating charged particles, which is based on the use of a wake field arising behind an electron bunch or a sequence of bunches passing through a waveguide-dielectric structure (DS), is currently being actively studied theoretically and experimentally [1 - 3].

The main element of the DS is a cylindrical or rectangular copper waveguide filled inside with a dielectric with a vacuum channel along the axis. In the traditional wakefield acceleration scheme, a short electron bunch with a large charge (up to $100 \mathrm{nC}$ ), when flying in a vacuum channel, generates the wake mode of Cherenkov radiation. Following it with a delay of $\sim \lambda / 2$, where $\lambda$ is the wavelength of the excited mode, a bunch with high energy but low charge is accelerated in this field. Experiments at SLAC [4] have shown that the accelerating field in the dielectric channel can reach $1.5 \ldots 2 \mathrm{GV} / \mathrm{m}$.

But traditional schemes of wake acceleration in DS are technically complex. And one of the main difficulties is the creation and precise injection of the accelerated bunch into the accelerating phase of the wake wave. In our opinion, this problem slows down the development of the wake acceleration method.

Earlier, in [5], the possibility of additional acceleration in the resonator structure of a linear accelerator of individual bunches of relativistic electrons was experimentally shown. This requires deflecting fields of the nanosecond range of duration and large amplitude.

In [6], it was proposed to use a phase shifter to change the phase of the wave in the resonator by $\pi$ radians, which will lead, in the steady state, to the entry of electron bunches into the accelerating phase of the wave. However, the proposal was not implemented due to the technical impossibility of changing the phase at the required speed.

This paper presents some results of experimental studies of the excitation of wake fields and the acceleration of electrons in DSs of circular and rectangular cross sections. The wake fields in the DS were excited by a regular sequence of relativistic electron bunches.
An increase in the amplitude of that harmonic was observed, the wavelength of which is equal to the doubled bunch length. Analysis of the position of the bunch in the field of this harmonic showed the possibility of accelerating a small part of the electrons located at its trailing edge of the bunch, simultaneously in the accelerating and focusing phases of the wake wave. Accelerated electrons were observed experimentally in DSs of circular and rectangular cross sections. A simple physical model of the increase in the amplitude of this harmonic is given.

The paper also considers a method for accelerating electrons by a wake field in passive DSs.

The essence of the proposed acceleration method lies in the fact that after passing through a certain part of the DS, and the excitation of a wake wave in it, the paths of the wave and electron bunches diverge. The electron bunches continue to move straight, but the number of electrons in the bunches decreases significantly as they pass through small holes in the walls of the waveguides. The "cut off" electrons enter the second part of the DS while continuing to move straight. The wake wave, on the other hand, enters the second part of the DS passing a longer path. The path length of the wake wave is longer than the path of electrons by half the waveguide wavelength.

\section{PARAMETERS OF ELECTRONS BUNCHES INJECTED INTO DS}

In experiments on accelerating a part of electrons of bunches, we used the "Almaz-2" accelerator with an electron energy of $3 \ldots 4.5 \mathrm{MeV}$. The beam consists of a sequence of 6000 electron bunches with a pulse duration of $2 \mu \mathrm{s}$ and a bunch repetition period. $\mathrm{T} \approx 360 \mathrm{ps}$. The charge of each bunch is $\mathrm{q}=0.1 \ldots 0.16 \mathrm{nC}\left(\mathrm{I}_{\mathrm{b}} \leq 3 \mathrm{~A}\right)$.

A characteristic feature of the accelerator is the ability to change the width of its energy spectrum (the energy distribution function of electrons in bunches) with a slight change in the operating frequency of the accelerator. The phase size of the bunches, measured in the middle of the operating frequency range using passive resonators [7], is shown in Fig. 1. 


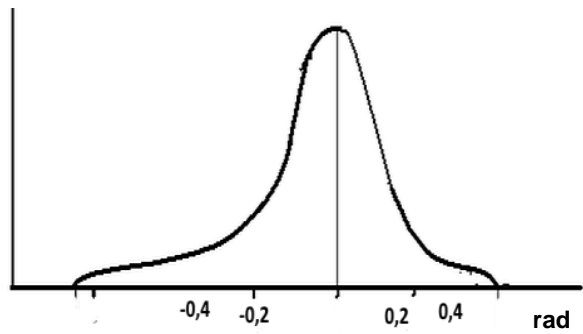

Fig. 1. Average phase size of the bunch

According to [7] $80 \%$ of electron bunches occupy a phase volume of about $20^{\circ}$.

The phase size of bunches for accelerators similar to "Almaz-2" was also measured using high-frequency separators in $[8,9]$, the phase "half-width" is $32^{\circ}$. About $90 \%$ of electrons have a phase size of $\sim 50^{\circ}$ (bunch length $\sim 1.6 \mathrm{~cm}$. The effect of the width of the energy spectrum of bunches on the length of bunches is observed. The accelerator and the interaction region are located at some distance from each other. Between them there is an energy analyzer, a pumping unit, etc. (there is a drift zone). At our electron energies and energy spectrum width, it is necessary to take into account the expansion of bunches due to the difference in speed of particles with nominal energy and particles with minimum and maximum energy.

The possibility of changing the width of the energy spectrum and the duration of electron bunches expands the range of experimental studies.

\section{EXCITATION OF A WAKEFIELDS IN A DS}

The excitation of a wakefield by a sequence of electron bunches in a DS with a circular and rectangular cross-section was studied earlier [10 - 12].

In $0.1 \mu \mathrm{s}$, after the start of injection of a sequence of electron bunches into the resonator DS (injection time of the first 300 bunches), the increase in the amplitude of the longitudinal component of the wake field stops and a steady state of field excitation sets in.

The experiments were carried out in the resonator mode of the DS operation. [3, 10]. For this, a cap with a titanium foil $50 \mu \mathrm{m}$ thick, transparent for relativistic electrons, was installed at the exit of the structure.

With the exception of electron bunches, no other particles or fields were injected into the DS during the experiments. Therefore, the structure can be considered passive. In this case, the acceleration of some part of the electrons, due to the redistribution of energy between the particles, can be considered self acceleration.

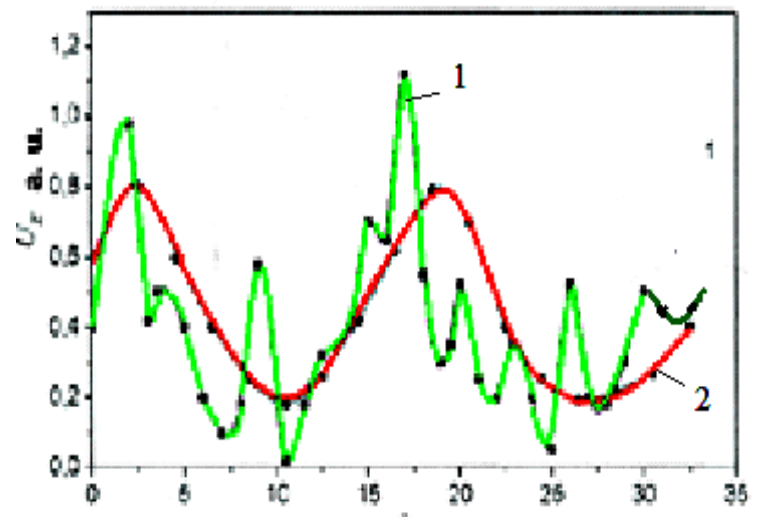

Fig. 2. Longitudinal component of the wake field
In the steady state, using a pin probe, the amplitude and distribution of the longitudinal component of the field strength were measured. Studies have shown that oscillations of the $\mathrm{E}_{01}$ type with a wavelength of $11.25 \mathrm{~cm}$ (at the repetition rate of the bunches) and $\mathrm{E}_{03}$ with a wavelength of $3.56 \mathrm{~cm}$ (at three times the repetition rate of the bunches) have the highest amplitude. Fig. 2 shows the signal obtained by moving the probe along the axis of the resonator behind the dielectric insert - curve 1 . The isolated signal of the first harmonic is shown in curve 2 . Studies using a cone transition and an out-of-limit, for the first mode, waveguide confirmed the presence and significant amplitude of the third harmonic.

The experiment was carried out with a DS of a circular cross section. A fluoroplastic sleeve $45 \mathrm{~cm}$ long was used as a dielectric; its outer diameter was $2 \mathrm{~b}=8.6 \mathrm{~cm}$, the hole on the DS axis had a diameter of $2 \mathrm{a}=2.2 \mathrm{~cm}$. The structure was tightly inserted into a circular waveguide $100 \mathrm{~cm}$ long. The width of the energy spectrum of the beam was $\delta \mathrm{W} \sim 12 \%$, the calculated length of the bunch is $\ell_{\mathrm{bu}} \sim 1.8 \mathrm{~cm}$. (The length of the bunch is close to half the waveguide wavelength of the third harmonic).

Earlier, in work [13], it was shown that in a dielectric resonator the amplitude of the wake wave will be maximum if its wavelength is equal to the doubled length of the electron bunches that excite this field. When a sequence of electron bunches were injected into the plasma formed by the bunches themselves upon their injection into a neutral gas [14], the predominant excitation of a harmonic with a wavelength equal to twice the bunch length was also observed.

This amplification of one of the harmonics does not correspond to the traditional frequency response (amplitude-frequency characteristic) built for a sequence of bunches with a duty cycle of $Q=6$.

However, there is a mechanism for increasing the amplitude for harmonics, which depends on the duration of the bunches exciting the field.

\section{DEPENDENCE OF THE DYNAMIC FACTOR ON THE FORCE PULSE DURATION}

Dinamic factor(DF)- $\mu$, with power excitation, is the ratio of the amplitude of the forced vibrations to the static amplitude [15].

As a rule, the DF is determined by the increase in the amplitude of the forced vibrations of the system from the frequency of the harmonic external force. In this case, the DF depends only on the frequency ratio. But, in our case, the Coulomb field excited by electron bunches should be considered not harmonic oscillations of the field strength; and individual field pulses with a duration of $\tau_{\mathrm{f}}=60 \mathrm{ps}$ and a period of $360 \mathrm{ps}$. Bunches are injected into the DS, which is designed to excite harmonics with a period of $\mathrm{T}_{\mathrm{s}}$ equal to: $360 \mathrm{ps}$ for the first harmonic, $180 \mathrm{ps}$ for the second harmonic, $120 \mathrm{ps}$ for the third, etc.

In the case of the action of short (in comparison with the period of natural oscillations) impulses of force, the DF depends on the ratio of the duration of the impulse of the force to the period of natural oscillations $[16,17]$. 
In Fig. 3 shows the dependence of the DF on $\tau_{\mathrm{f}} / \mathrm{T}_{\mathrm{s}}$. In [18], a table is given for the values $\tau_{\mathrm{f}} / \mathrm{T}_{\mathrm{s}}$ of the DF. The DF begins to have a noticeable effect on the system at $\tau_{\mathrm{f}} / \mathrm{T}_{\mathrm{s}}>0.15$. This dependence will be valid when the force impulse is rectangular.

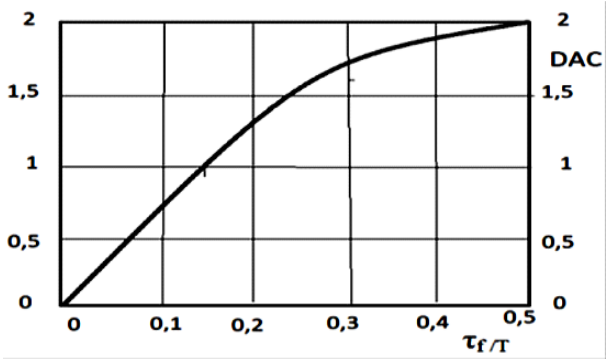

Fig. 3. Dependence of the DF on the ratio of the force pulse duration to the period of natural oscillations

The increase in the DF is a response to each individual impulse of force. When they are repeated, the amplitude of the forced oscillations also increases due to the replication coefficient $\beta$ [18]. This coefficient characterizes the increase in the effect of repetitive impulses. When the pulse repetition rates $-\omega_{\mathrm{f}}$ coincide with the natural frequency of the system $\omega_{\mathrm{s}}$, or their multiplicity $\left(\omega_{\mathrm{s}}=\mathrm{n} \omega_{\mathrm{f}}\right.$, where $\left.\mathrm{n}=1,2 \ldots\right)$, a resonance occurs.

The repetition factor is, as in the case of harmonic oscillations, the requirement for the frequency of harmonics to be the frequency of the external force.

In our experiments (at a distance between the exit of the accelerator and the DS of $\sim 20 \mathrm{~cm}$ ), the period of the third harmonic is equal to twice the length of the bunches and, one could expect an increase of the DF by two times. But, the value of the DF largely depends on the shape of the force pulse and, the discrepancy between the shape of the real pulse and the shape adopted in the calculation leads to a decrease in the dynamic coefficient. In our case, the amplitude of the third harmonic is increased by $\sim 1.5$ times.

Thus, if the system is acted upon by short impulses of force $\left(\tau_{\mathrm{f}}<\mathrm{T}_{\mathrm{s}}\right)$, then, in order to obtain the maximum amplitude of oscillations, it is necessary that the duration of the impulse of the force be equal to half the period of the natural oscillations of the system, and the frequency should be equal to or a multiple of the frequency of impulses of the force $\omega_{\mathrm{s}}=\mathrm{n} \omega_{\mathrm{f}}$ and $\omega_{\mathrm{s}}=\pi / \tau_{\mathrm{f}}$ or, for the period $T_{s}=T_{f} / n$ and $T_{s}=2 \tau_{f}(1)$

\section{ACCELERATION OF A PART OF ELECTRONS OF ELECTRONIC BUNCHES}

The first and third harmonics have the highest amplitudes in the DS, their superposition is observed, and the interaction of these modes with bunches can be considered separately.

When the bunches of the third harmonic of the repetition rate are excited, their length is equal to half the won wavelength of the excited field, and in the steady state mode, the "center of gravity" of the bunches should be in the region of the field maximum in the decelerating phase of the wave, Fig. 4.

In this case, according to [19], the ratio between the transverse and longitudinal components of the wake field can be determined from: $\mathrm{E}_{\mathrm{r} \max } / \mathrm{E}_{\mathrm{z} \max }=(\pi \mathrm{a}) / \lambda$, for the third harmonic the transverse and longitudinal components of the wake field are close in magnitude.

Based on the position of the bunch in the wake wave, it can be seen that some of the electrons at the leading and trailing edges of the bunch are in the accelerating phase of the longitudinal field of the wave. However, the electrons at the leading edge are also simultaneously in the defocusing phase of the transverse component of the field and should rather quickly leave the beam region. The trailing edge electrons are simultaneously in the accelerating and focusing phases of the wake wave and can receive additional acceleration and focus. The wake wave and bunches, in the considered part of the DS, move in the same direction. This, in our opinion, is the mechanism for the acceleration of a small number of electrons observed experimentally.

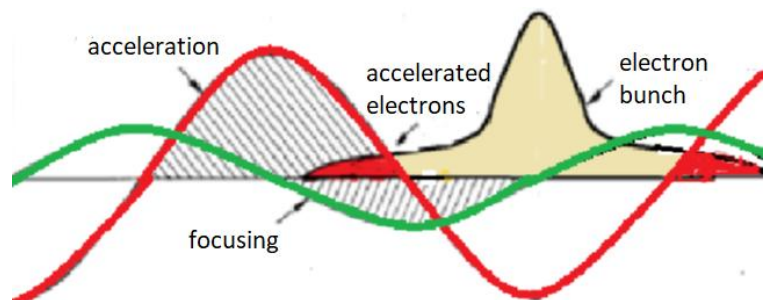

Fig. 4. Position of the bunch in the decelerating phase of the wake wave

The bunch electrons are in different phases of the longitudinal and transverse fields. This leads to a change in the shape of the clot - its "sharpening". The possibility of changing the shape of bunches upon excitation of wake fields was theoretically shown in [20]. Experimentally, the change in the shape of the bunches and the appearance of accelerated electrons were observed both in a DS with a rectangular cross section [eleven]. The change in the shape of the bunches is more clearly observed in the DS with a circular cross section.

In Fig. 5 shows imprints on glass plates of bunches deployed in a transverse magnetic field in the absence (1) and presence (2) of a dielectric insert in the waveguide. The dimensions of the DS were the same as in Section 2. Accelerated electrons were observed at the "tip" of the leading front of bunches.

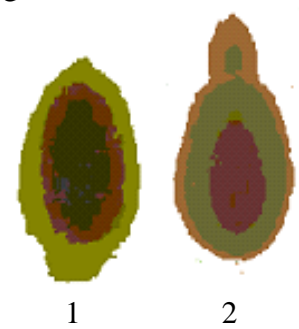

Fig. 5. Imprints on glass plates of clumps deployed in a transverse magnetic field in the absence (1) and presence (2) of a dielectric insert

The influence of the field of the first harmonic on the motion of bunches is not decisive. In the steady-state regime, the field of the first harmonic cannot lead to the simultaneous acceleration and focusing of any part of the bunch.

Based on (1), in order to increase the amplitude of the wake field excited by the bunches and the possible acceleration of a certain number of electrons, the DS should meet the following requirements: The wave- 
length of the first harmonic of the DS should be a multiple of the bunch repetition rate and close to twice the bunch length (for example, take $\ell_{\mathrm{b}} \sim 1.5 \mathrm{~cm}$ ). We find the dimensions of the dielectric insert using the expression for the excited modes from [18]:

$$
\lambda_{\mathrm{n}}=4(\mathrm{~b}-\mathrm{a}) / \mathrm{n} \text {; for }(\varepsilon-1) \sim 1 \text {. }
$$

The wave of $3 \mathrm{~cm}$ is considered as the main one, $\varepsilon$ is taken equal to 2.1. The thickness of the dielectric insert in this case should be $0.7 \mathrm{~cm}$, and with a channel radius of $1 \mathrm{~cm}$, the outer radius of the insert is $1.7 \mathrm{~cm}$, the same inner radius of the waveguide in which the dielectric structure is placed. The critical wavelength for $\mathrm{E}_{01}$ in a waveguide with a dielectric insert is $\lambda_{\text {cd }} \sim 6.5 \mathrm{~cm}$. The waveguide wavelength is $\lambda_{\mathrm{vd}} \sim 2.65 \mathrm{~cm}$. It is rational to make the structure $21.2 \mathrm{~cm}$ long.

\section{SCHEMES OF DS FOR ACCELERATION OF PART OF ELECTRONS OF CLUSTERS WITH A DELAY MODE}

For a more reliable and controlled acceleration of a part of electrons in bunches, one can use the DS scheme shown in Fig. 6.
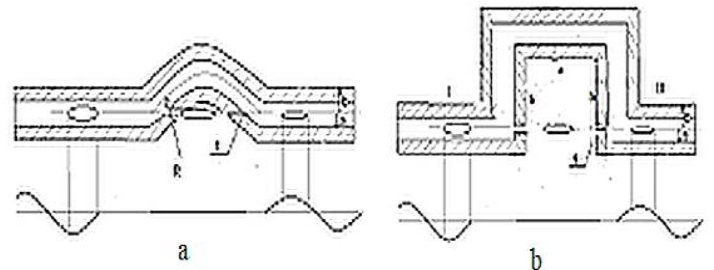

Fig. 6. Schematic diagram of a $D S$

for accelerating a part of electrons in bunches: smooth rotation of the waveguide $(a)$, rotation of the waveguide by $90^{\circ}(\mathrm{b})$

The DS is designed to accelerate a part of the electrons of the bunches in two possible variants of the delay of the wake wave relative to the accelerated part of the electrons. The circuits are identical, with the exception of the wave delay unit and can be used for DSs of both circular and rectangular cross sections.

The excitation of the wake wave and the position of the bunches in the first part of the structure are described in the previous section. After leaving the first part of the DS, the paths of the wave and electron bunches diverge. The electron bunches continue to move straight, but the number of electrons in the bunches decreases significantly as they pass through the holes in the walls of the waveguides. The "cut off" electrons enter the second part of the DS while continuing to move straight. The wake wave enters the second part of the DS passing a longer path. The outer and inner diameters of the second part of the DS are the same as in its first part $\mathrm{a}=1 \mathrm{~cm}, \mathrm{~b}=1.7 \mathrm{~cm}$, but its length is shorter than the length of the first part by the length of the delay unit: $\ell_{\mathrm{vf}}-1_{\mathrm{e}}=1.32 ; 4$ or $6.6 \mathrm{~cm}$. It is assumed that with the radius of collimating holes $\approx 3 \ldots 4 \mathrm{~mm}$, the accelerated bunches will have $10 \ldots 15 \%$ of the charge of the bunches located in the first part of the DS.

Thus, bunches with a small number of electrons fall into the accelerating phase of the wake wave at the entrance to the second part of the DS, and can be accelerated in it.

\section{CONCLUSIONS}

In this work, for the first time experimentally shown the importance of taking into account the length of the bunches in the excitation of wake fields in the DC. The amplitude of the wakefield harmonic with a wavelength equal to twice the length of the bunches increases when a long sequence of bunches is used. In this case, a small number of accelerated electrons were also observed. The paper proposes a simple physical model of this phenomenon. It consists in the fact that the field excited by the bunches must be considered as separate pulses, and not as harmonic oscillations $(Q=6)$. In this case, the amplitude of the harmonic increases, for which the period is equal to twice the duration of the bunch. This, in turn, causes the acceleration of some of the electrons located at the trailing edge of the bunch, simultaneously in the accelerating and focusing field of the wave.

Also shown is a diagram of the acceleration of a part of the electrons of the bunches during the delay of the wake wave, excited by the bunches earlier, relative to the accelerated part of the electrons by half the wavelength. But, unfortunately, in both cases the acceleration is limited by the low phase velocity of the wave in the DW. Therefore, further it is desirable to conduct studies of the possibility of increasing the phase velocity of the wave. In a round waveguide, for example, this can be done by decreasing the radius of the waveguide. In this case, the critical wavelength will decrease and an increase in the phase velocity.

The study was supported by the program of the National Academy of Sciences of Ukraine "Advanced Research in Plasma Physics, Controlled Thermonuclear Fusion and Plasma Technologies", project P-1/63-2020.

\section{REFERENCES}

1. T.C. Marshall, J.-M. Fang, J.L. Hirshfield, S.J. Park // AIP Conf. Proc. 2001, № 569, p. 31.

2. Chunguang Jing Dielectric Wakefield Accelerators // Reviews of Accelerator Science and Technology. 2016, v. 9, p. 127-149.

3. V.A. Balakirev, I.N. Onishchenko, D.Yu. Sidorenko, G.V. Sotnikov. Acceleration of charged particles by wake fields in a dielectric resonator with a channel for an exciting bunch // Technical Physics Letters. 2003, v. 29, № 14, p. 39-45.

4. M.C. Thompson, H. Badakov, G.T. Rozenzweig. Preliminary Results from the UCLA/SLAC UltraHigh Gradient Cerenkov Wakefield // Proceedings Trim Sise. UCRL-PROC-220696, 2006.

5. V.A. Vishnyakov, V.V. Zakutan, V.A. Kushnir, A.M. Shenderovich, et al. Experimental study of obtaining large accelerating fields and additional acceleration of the beam of a linear resonant accelerator in a system of passive resonators // ZhTF. 1987, v. 57, issue 8, p. I549-I555.

6. B.Yu. Bogdanovich, A.V. Shalnov. Title Linacs with Self-Acceleration of Bunched Beam // 1st European Particle Accelerator Conference. Rome, Italy, 7-11 Jun 1988, p. 473.

7. A.I. Zykov, V.A. Kushnir, V.P. Roiasko, G.L. Frsov. Phase analysis of a linear resonant accelerator beam 
using passive resonators // Problems of Atomic Science and Technology. 1989, № 5, p. 65-67.

8. G.M. Ivanov, V.V. Pilipenko, L.A. Makhnenko, A.N. Dovbnya. Measurement of charge distribution over phases in bunches on a linear accelerator with a traveling wave // Sat. "Linear accelerators" of the Physicotechnical Institute of the Academy of Sciences of the Ukrainian. Kharkov, 1967, p. 81-88.

9. A.I. Zykov, G.D. Kramskoy, E.K. Ostrovsky. Measurement of the phase spectrum of accelerated electrons using a high-frequency separator // ZhTF, 1969, v. 39, № 6, p. 1007-1010.

10. V.A. Kiselev, A.F. Linnik, T.S. Marshall, I.N. Onischenko, N.I. Onischenko, G.V. Sotnikov, V.V. Uskov. Research on Wake-field Excitation in a Cylindrical Dielectric Waveguide and Resonator by a Sequence of Electron Bunches // Strong microwave in plasma. N.-Novgorod, Russia, 2006, v. 1, p. $303-$ 310.

11. V.A. Kiselev, A.F. Linnik, V.I. Mirny, I.N. Onishchenko, V.V. Uskov. On the acceleration of electrons upon excitation of wake fields in dielectric structures // Problems of Atomic Science and Technology. Series "Plasma Electronics and New Methods of Acceleration”. 2008, № 4, p. 70-72.

12. V.A. Kiselev, J.L. Hirshfield, A.F. Linnik, T.S. Marshall, I.N. Onischenko, N.I. Onischenko, G.V. Sotnikov, V.V. Uskov. Wakefield Excitation by a Sequence of Electron Bunches in a Rectangular Waveguide Lined with Dielectric Slabs // $12 \mathrm{Ad}$ vanced Accelerator Concept Workshop, Lake Gene- va, Wisconsin, 10-15 July 2006. Conference Proceedings. 2006, v. 877, p. 851-858.

13. K.V. Galaydych, P.I. Markov, G.V. Sotnikov. Excitation of wake fields by extended electron bunches in a dielectric resonator // Radio engineering and electronics. 2009, v. 54, №10, p. 1258-1265.

14. A.F. Linnik, I.N. Onishchenko, V.I. Pristupa, G.V. Sotnikov, et al. Excitation of the repetition frequency harmonics of electron banches at the injection to atmosphere // Problems of Atomic Science and Technology. Series "Nuclear Physics Investigations”. 2018, № 3, p. 49-52.

15. I.I. Vulfson. A short course in the theory of mechanical vibration. M.: "VNTR", 2017, p. 233.

16. Introduction to Structural Impact. http://www.pdhonline.org/.

17. N.G. Suryanov, A.F. Doshchenko, P.A. Whitebeard. Theoretical foundations of machine dynamics. Odessa: "OGPU", 2000, p. 100.

18. B.V. Persov. Dynamic loads in structures. Preprint № 92-70. Novosibirsk: “BINP”, 1992, 12 p.

19. C. Jing. J. Power, and A. Zholents. Dielectric Wakefield Accelerator to Drive the Future FEL Light Source // ANL/APS/LS-326, March 21, 2011.

20. K.V. Lotov, V.I. Maslov, I.N. Onishchenko. Long Sequence of Relativistic Electron Bunches as a Driver in Wakefield Method of Charged Particles Acceleration in Plasma // Problems of Atomic Science and Technology. Series "Plasma Physics". 2010, № 6, p. 103-107.

Article received 11.10.2021

\section{УСКОРЕНИЕ ЧАСТИ ЭЛЕКТРОНОВ ЭЛЕКТРОННЫХ СГУСТКОВ В ДИЭЛЕКТРИЧЕСКОЙ СТРУКТУРЕ}

\section{А.Ф. Линник, И.Н. Онищенко, О.Л. Омелаенко, В.И. Приступа, Г.В. Сотников, В.С. Ус}

Представлены некоторые результаты экспериментальных исследований возбуждения кильватерных полей и ускорения электронов в волноводно-диэлектрических структурах при инжекции в них последовательности электронных сгустков. Эксперименты показали увеличение амплитуды кильватерной волны и ускорение небольшой части электронов при равенстве длины волны возбужденного поля удвоенной длине сгустка. Дана простая физическая модель наблюдаемого явления. Также в работе предложен способ ускорения части каждого электронного сгустка в установившемся режиме резонаторной диэлектрической структуры. Часть электронов «вырезается» коллиматором и попадает в ускоряющую фазу возбужденной ранее кильватерной волны. Волна смещается за счет разницы в расстояниях, проходимых волной и ускоряемой частью электронов.

\section{ПРИСКОРЕННЯ ЧАСТИНИ ЕЛЕКТРОНІВ ЕЛЕКТРОННИХ ЗГУСТКІВ У ДІЕЛЕКТРИЧНІЙ СТРУКТУРІ}

\section{А.Ф. Лінник, І.М. Оніщенко, О.Л. Омелаєнко, В.І. Приступа, Г.В. Сотніков, В.С. Ус}

Представлені деякі результати експериментальних досліджень збудження кільватерних полів і прискорення електронів в хвилеводно-діелектричних структурах при інжекції в них послідовності електронних згустків. Експерименти показали збільшення амплітуди кільватерної хвилі і прискорення невеликої частини електронів при рівності довжини хвилі збуджуваного поля подвоєній довжині згустку. Дана проста фізична модель цього явища. Також у роботі запропоновано спосіб прискорення частини кожного електронного згустку в сталому режимі резонаторної діелектричної структури. Частина електронів «вирізується» коліматором і потрапляє в прискорюючу фазу збудженої раніше кільватерну хвилю. Хвиля зміщується за рахунок різниці в відстанях, що проходять хвиля і прискорювана частина електронів. 